\title{
Positive end-expiratory pressure titration in COVID-19 acute respiratory failure: electrical impedance tomography vs. $\mathrm{PEEP} / \mathrm{FiO}_{2}$ tables
}

\author{
Nicolò Sella ${ }^{1 \dagger}$, Francesco Zarantonello $^{2 \dagger}$, Giulio Andreatta ${ }^{1}$, Veronica Gagliardi ${ }^{1}$, Annalisa Boscolo ${ }^{2}$ and
} Paolo Navalesi ${ }^{1,2^{*}}$

Keywords: COVID-19, Acute respiratory failure, Mechanical ventilation, Positive end-expiratory pressure, Electrical impedance tomography

To the Editor,

Hypoxemic acute respiratory failure (hARF) secondary to COVID-19 presents with heterogeneous features depending on several determinants, such as the extent of intravascular microthrombosis, superinfections, and other complications [1, 2]. The easiest approach for setting positive end-expiratory pressure (PEEP) and inspiratory oxygen fraction $\left(\mathrm{FiO}_{2}\right)$ is using $\mathrm{PEEP} / \mathrm{FiO}_{2}$ tables $[3,4]$. However, because the magnitude of lung recruitability is variable, personalizing PEEP would be desirable [1]. Electrical impedance tomography (EIT) offers this opportunity by bedside estimating both alveolar collapse and lung overdistension throughout a decremental PEEP trial [5].

This investigation (Ethics Committee approval: Ref: 4853/AO/20-AOP2012) aims to assess the agreement between EIT-based PEEP values and those recommended by the higher and lower $\mathrm{PEEP} / \mathrm{FiO}_{2}$ tables [6] in a series of consecutive intubated COVID-19 hARF patients, admitted to intensive care unit at our institution. Written informed consent was obtained from all patients.

\footnotetext{
* Correspondence: paolo.navalesi@unipd.it

${ }^{+}$Nicolò Sella and Francesco Zarantonello contributed equally to this work. 'Department of Medicine - DIMEDD, University of Padua, via V. Gallucci 13, 35125 Padua, Italy

${ }^{2}$ Anaesthesia and Intensive Care Unit, Padua University Hospital, via V. Gallucci 13, 35125 Padua, Italy
}

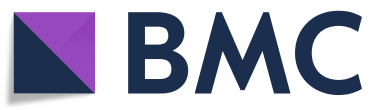

(c) The Author(s). 2020 Open Access This article is licensed under a Creative Commons Attribution 4.0 International License, which permits use, sharing, adaptation, distribution and reproduction in any medium or format, as long as you give appropriate credit to the original author(s) and the source, provide a link to the Creative Commons licence, and indicate if changes were made. The images or other third party material in this article are included in the article's Creative Commons licence, unless indicated otherwise in a credit line to the material. If material is not included in the article's Creative Commons licence and your intended use is not permitted by statutory regulation or exceeds the permitted use, you will need to obtain permission directly from the copyright holder. To view a copy of this licence, visit http://creativecommons.org/licenses/by/4.0/. The Creative Commons Public Domain Dedication waiver (http://creativecommons.org/publicdomain/zero/1.0/) applies to the data made available in this article, unless otherwise stated in a credit line to the data.

We performed 15 decremental PEEP trials through a dedicated device (Pulmovista500, Dr ger-Medical, Germany) and subsequently analyzed pulmonary perfusion distribution [5]. Five patients were evaluated in a prone position. EIT optimal PEEP (PEEP EIT $_{\text {) was defined }}$ as the best compromise between lung collapse and overdistension [5]. All patients were deeply sedated without spontaneous breathing efforts and ventilated in volume control mode with lung-protective settings [3]. PEEP EIT was compared with PEEP from higher and lower PEEP/ $\mathrm{FiO}_{2}$ tables [6]. Data, expressed as median and interquartile ranges or $95 \%$ confidence interval $(\mathrm{CI})$, were analyzed with the Mann-Whitney test for comparisons and Spearman rank test for correlations, considering $p$ values $<0.05$ significant. The Bland-Alman analysis was also performed.

Patients had received invasive ventilation for 12.0 (10.0-14.5) days. Patients' age was 63 (56-78) years, while body mass index (BMI) was $26.2(25.4-30.9) \mathrm{kg} /$ $\mathrm{m}^{2}$. Pulmonary shunt and dead space, as assessed by EIT [5], were $4 \%(2-6 \%)$ and $27 \%(23-36 \%)$, respectively. Ddimer was increased [759 (591-1208) $\mathrm{mcg} / \mathrm{L}]$, while procalcitonin blood concentration was nearly normal $[0.53$ $(0.34-0.70) \mathrm{mcg} / \mathrm{L}]$. PEEP EIT $_{\text {was }} 12(10-14) \mathrm{cmH}_{2} \mathrm{O}$ and was significantly different from PEEP values of both higher [17 (16-20) $\left.\mathrm{cmH}_{2} \mathrm{O}, p<0.001\right]$ and lower [9 (810) $\left.\mathrm{cmH}_{2} \mathrm{O}, p=0.049\right] \mathrm{PEEP} / \mathrm{FiO}_{2}$ tables. The Bland- 

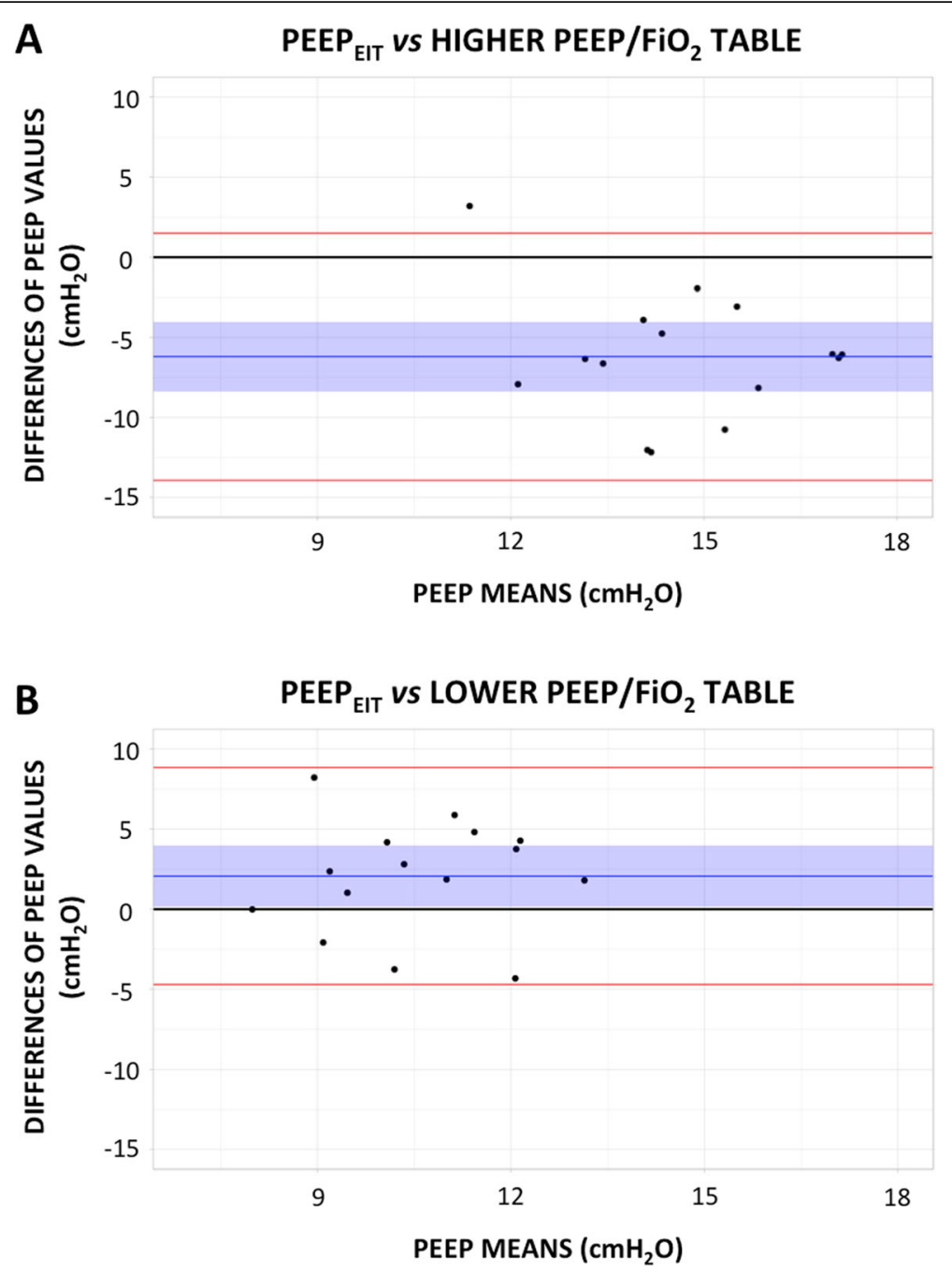

Fig. 1 Bland-Altman plot, evaluating the agreement between PEEP EIT and the PEEP values proposed by the higher (a) and lower $(\mathbf{b})$ PEEP/FiO 2 tables from the ALVEOLI trial [6]. X-axis: average of paired measurements. Y-axis: difference between paired measurements. The blue line and blue shaded area: bias and 95\% confidence interval of the bias between PEEP EIT and the PEEP values suggested by PEEP/FiO 2 tables. Red lines: upper and lower limits of agreement between methods

Altman analysis showed that PEEP ${ }_{\text {EIT }}$ was 6.2 [CI 3.98.4] $\mathrm{cmH}_{2} \mathrm{O}$ smaller and 2.0 [CI 0.1-4.0] $\mathrm{cmH}_{2} \mathrm{O}$ greater than PEEP levels recommended, respectively, by the higher and lower PEEP/FiO ${ }_{2}$ tables (Fig. 1). No correlation was found between PEEP $\mathrm{EIT}_{\text {T }}$ and $\mathrm{FiO}_{2}(p=0.789)$ (Fig. 2). The loss of lung compliance secondary to lung collapse observed with PEEP values from the lower $\mathrm{PEEP} / \mathrm{FiO}_{2}$ table $[7.0 \%(3.2-8.7 \%)]$ was not significantly greater, compared to that obtained with PEEP EIT $_{3}[3.0 \%(2.0-4.7 \%)]$ ( $p=$ 0.077). Conversely, the loss of lung compliance consequent to lung overdistension was significantly greater with PEEP values from the higher $\mathrm{PEEP} / \mathrm{FiO}_{2}$ table $[15.5 \%$ (11.021.5\%)] than with PEEP $_{\text {EIT }}[4.0 \%(3.0-4.7 \%)](p<0.001)$.

In contrast to our results, a recent study, utilizing the same EIT device in intubated COVID-19 hARF patients, reported much higher values of PEEP EIT $_{\text {[ }}$ (16-22)
$\mathrm{cmH}_{2} \mathrm{O}$ ], closer to those indicated by the higher PEEP/ $\mathrm{FiO}_{2}$ table, though without significant correlation [4]. These differences are partly explained by the different criteria for PEEP EIT selection, which in that study was set above the value indicated by the built-in algorithm corresponding to the least lung collapse and overdistension [4]. Also, compared to our study, they enrolled more obese patients, as indicated by the higher BMI $\left[30.0(27.0-34.0) \mathrm{kg} / \mathrm{m}^{2}\right]$ [4]. Not reported in that study [4], our patients showed increased D-dimer and high fraction of pulmonary dead space, while shunt fraction and procalcitonin were nearly normal, suggesting predominant lung vascular disruption.

In conclusion, we confirm the rationale for individualized PEEP setting in COVID-19 patients intubated for 


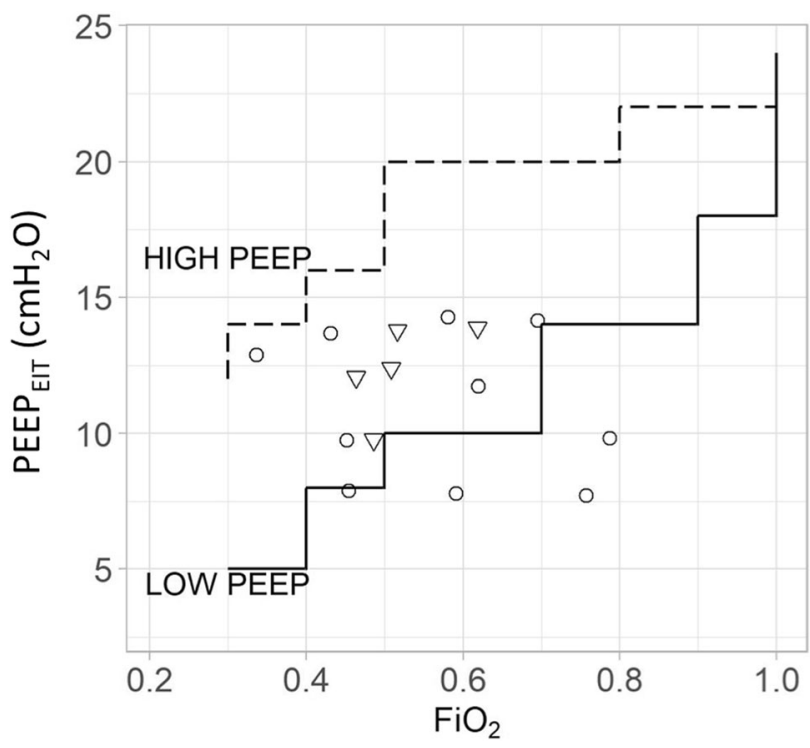

\section{Position}

$\nabla$ Prone

○ Supine

Fig. 2 Spearman correlation between $\mathrm{PEEP}_{\mathrm{EIT}}$ and $\mathrm{FiO}_{2}(R=0.075, p=0.789)$. Continuous line: lower $\mathrm{PEEP} / \mathrm{FiO}_{2}$ table. Dashed line: higher $\mathrm{PEEP} / \mathrm{FiO}_{2}$ table

hARF. Whether EIT is the best technique for this purpose and the overall influence of personalizing PEEP on clinical outcome remain to be determined.

\section{Acknowledgements}

We feel indebted with all ISTAR3-ICU personnel who made this work possible.

\section{Authors' contributions}

Concept and design: NS, FZ, and PN. Acquisition, analysis, or interpretation of the data: FZ, GA, VG, and NS. Drafting of the manuscript: FZ, VG, NS, and AB. Critical revision of the manuscript for important intellectual content: PN, GA, and AB. Statistical analysis: FZ and NS. Supervision: PN. The authors read and approved the final manuscript.

\section{Funding}

None declared.

\section{Availability of data and materials}

The data that support the findings of this study are available from the corresponding author, $\mathrm{PN}$, upon request.

\section{Ethics approval and consent to participate}

The study was approved by the Local Ethical Committee: Comitato Etica per la Ricerca Clinica, Azienda Ospedale Università di Padova, Ref:4853/AO/20AOP2012. Written informed consent was obtained from all patients.

\section{Consent for publication}

Written informed consent was obtained for all patients.

\section{Competing interests}

PN received royalties from Intersurgical for Helmet Next invention and speaking fees from Philips, Resmed, MSD, and Novartis.

The other authors have no competing interests to declare.

The experimental software for EIT perfusion assessment was kindly provided by Dräger Medical, Germany, without any financial supports.
Received: 3 August 2020 Accepted: 12 August 2020

Published online: 01 September 2020

\section{References}

1. Fan E, Beitler JR, Brochard L, et al. COVID-19-associated acute respiratory distress syndrome: is a different approach to management warranted? Lancet Respir Med. 2020:8(8):816-21. https://doi.org/10.1016/S22132600(20)30304-0.

2. Boscolo A, Spiezia L, Correale C, et al. Different hypercoagulable profiles in patients with COVID-19 admitted to the internal medicine ward and the intensive care unit [published online ahead of print, $2020 \mathrm{Jul}$ 23]. Thromb Haemost. 2020. https://doi.org/10.1055/s-0040-1714350.

3. Pasin L, Sella N, Correale C, et al. Regional COVID-19 Network for Coordination of SARS-CoV-2 outbreak in Veneto, Italy [published online ahead of print, 2020 May 15]. J Cardiothorac Vasc Anesth. 2020. https://doi. org/10.1053/j.jvca.2020.05.005.

4. van der Zee P, Somhorst P, Endeman H, Gommers D. Electrical impedance tomography for positive end-expiratory pressure titration in COVID-19related acute respiratory distress syndrome. Am J Respir Crit Care Med. 2020:202(2):280-4

5. Frerichs I, Amato MB, van Kaam AH, et al. Chest electrical impedance tomography examination, data analysis, terminology, clinical use and recommendations: consensus statement of the TRanslational EIT developmeNt stuDy group. Thorax. 2017;72:83-93.

6. Brower RG, Lanken PN, Maclntyre N, et al. Higher versus lower positive endexpiratory pressures in patients with the acute respiratory distress syndrome. NEJM. 2004:351:327-36.

\section{Publisher's Note}

Springer Nature remains neutral with regard to jurisdictional claims in published maps and institutional affiliations. 